\title{
Investigating shadows: a pedagogical intervention project with primary school children
}

Silvana Noversa, Cátia Abreu, Paulo Varela, Manuel F. Costa

Silvana Noversa, Cátia Abreu, Paulo Varela, Manuel F. M. Costa, "Investigating shadows: a pedagogical intervention project with primary school children," Proc. SPIE 9289, 12th Education and Training in Optics and

Photonics Conference, 92892M (17 July 2014); doi: 10.1117/12.2070750

SPIE Event: 12th Education and Training in Optics and Photonics Conference, 2013, Porto, Portugal 


\title{
Investigating shadows. A pedagogical intervention project with primary school children
}

\author{
Silvana Noversa ${ }^{\mathrm{a}, \mathrm{b}}$; Cátia Abreu ${ }^{\mathrm{a}, \mathrm{b}}$; Paulo Varela ${ }^{\mathrm{b}}$; Manuel F. M. Costa ${ }^{\mathrm{c}}$ \\ ${ }^{\mathrm{a}}$ Preschool teachers/master students \\ ${ }^{\mathrm{b}}$ Institute of Education, University of Minho, Campus de Gualtar, 4710-057 Braga, Portugal, \\ 'Centro de Física, University of Minho, Campus de Gualtar 4710-057 Braga, Portugal \\ pibvarela@ie.uminho.pt; mfcosta@fisica.uminho.pt
}

\begin{abstract}
This communication results from a pedagogical intervention project, carried out at a primary school in the district of Braga - Portugal. The intervention took place in a class of the $3^{\text {rd }}$ year, composed of 16 students, and it incorporated the practice of inquiry-based science teaching addressing the theme "Light Experiments", which is part of the "Environmental Studies" curricular area. Various class activities were planned and implemented concerning some of the factors that influence the shadow of an object, in order to find answers to the following three questions: a) will $3^{\text {rd }}$ year students, aged 7/8 years, be able to construct and execute an investigation strategy that involves manipulating and controlling variables? b) what are the main difficulties experienced by students in the designing and execution of such a strategy? c) how will students, in interaction with the teacher and with their peers, gradually design and execute their investigation strategy in order to respond to the problem formulated?

The project adopted an action research methodology. A careful record was kept of the events most relevant to the questions under study in each class. This data was used to prepare the class diaries - descriptive and reflective narratives prepared based on recorded audio and field notes made during participant observation in the context of the classroom. A content analysis of the diaries has identified a few elements that provide answers to the research questions raised. In order to plan and implement a research project with children in the 7/8 years old range require a high level of scaffolding to allow students to gradually build a coherent strategy to tackle the research problem. Teacher's role is crucial. The teacher, by questioning and inducing reasoning and discussion, promotes encourages and regulates the cognitive activity of students. Some level of autonomy should be given to the students in large group collaborative work.
\end{abstract}

Keywords: Collaborative and Reflexive Learning, Inquiry Based Science Education. Elementary Optics

\section{INTRODUCTION}

In science teaching, one of the approaches that have been suggested by the science curricula of many countries and by some international organizations is inquiry-based science education (IBSE). Inquiry teaching is the "intentional process of diagnosing problems, critiquing experiments and distinguishing alternatives, planning investigations, researching conjectures, searching for information, constructing models, debating with peers, and forming coherent arguments” [1, p. 4]. The National Research Council [2] identifies five attributes that learners will acquire from inquiry-based science teaching: a) engaging in scientifically oriented questions; b) giving priority to evidence in answering questions; c) formulating explanations based on evidence; d) connecting explanations to scientific knowledge, and e) communicating and justifying explanations. According to Drayton and Falk [3, p. 25], "The inquiry-based approach to science education [...] introduces students to science contents, including the process of investigation, in a context of reasoning, which gives science its dynamic nature and provides the logical framework that enables the understanding of scientific innovation and the evaluation of scientific claims. Inquiry is not process versus content; it is rather a way of learning content”. Inquiry teaching is an approach that enables the learning of concepts and the development of scientific processes [3]. Scientific inquiry encourages the development of problem solving, communication and thinking skills, as students pose questions about the natural world and then seek evidence to answer their questions [3]. The ability to question, hypothesize, design investigations and develop conclusions based on evidence gives all students the problem-solving, communication, and thinking skills they will need to claim their place in the 21st century world [2]. In this sense, one skill that all students should acquire is the ability to conduct an investigation where they keep everything else constant 
while changing one single variable. This ability provides a powerful general strategy for solving many problems encountered in the workplace and in everyday life [2, pp. 14-15].

However, in the majority of European countries, the reality of classroom practice is that these methods are being implemented by relatively few teachers [3] [4]. Reports from the European Commission continue to advocate the advantages of inquiry-based science education and its recommendations clearly promote the use of inquiry-based science teaching in Europe [5].

In Portugal, the situation is no different. Although the science curriculum of primary education suggests a teaching practice in which students should be "active observers, with the ability to discover, investigate, experiment and learn" [3, p. 102], this teaching practice is still only occasional, with only a residual expression in the teachers' pedagogical practices [4]. In light of this, the present study was conducted - a pedagogical intervention project in the field of science teaching, aimed at promoting an approach to science education based on an active and constructive role for the student, in a context of social interaction with peers and with the teacher [5] [6].

\section{OBJECTIVES}

The project for a pedagogical intervention in science teaching incorporates a practice of inquiry-based science teaching, addressing the theme "Light Experiments", part of the "Environmental Studies" curricular area of primary education. Various class activities were planned and implemented around some of the factors that influence the shadow of an object, in order to find answers to the following questions: a) Will 3rd year students, aged 7/8 years, be able to construct and execute an investigation strategy that involves manipulating and controlling variables? b) What are the main difficulties experienced by students in the designing and execution of such a strategy? c) How will students, in interaction with the teacher and with their peers, gradually design and execute their investigation strategy in order to respond to the problem formulated?

\section{METHODOLOGY}

The study adopted an action research approach. A pedagogical intervention in sciences was carried out with a class of the 3rd year, at a school located on the outskirts of the city of Braga - Portugal. The class was composed of 16 students, 10 boys and 6 girls, aged 7 to 8 years. For two months, 7 lessons were taught on the curricular topic "Light Experiments", amounting to a total of 15 hours of intervention in the classroom.

For each topic addressed, a teaching and learning plan was prepared, containing the following elements: i) learning goals; ii) materials needed for the groups to implement the planned activities; iii) guidelines for the teaching and learning process, and iv) a record sheet for each student. Each lesson, which corresponds to an action research cycle, begins with a teaching and learning plan that is implemented flexibly, according to the teaching and learning processes generated and promoted in the class reality. The classes were taught by the two authors of this poster, who, in collaboration with the class teacher, played the role both of researchers and teachers.

The data generated in the intervention was collected using two complementary methods, which were the field notes made by the researchers and the audio recordings of the lessons. This raw data was later compiled in the form of detailed narratives of the most relevant events that took place in the classroom - the class diaries. These constituted the principal method of recording data and, simultaneously, a strategy for reflection and for the modeling of the teaching and learning process [7] [8]. Additionally, tests were conducted to evaluate the learning acquired by the students and a questionnaire was proposed to parents/guardians, aiming to collect comments and reactions expressed by the students in the family context, concerning the nature of the intervention carried out in class.

\section{SOME RESULTS}

The data obtained from the various collection methods used is still in the process of treatment and analysis. However, through the interpretive content analysis on one of the class of diaries, it is possible to describe and illustrate how students, in interaction with the teacher and their peers, gradually design and execute each of the investigations conducted in the classroom.

\subsection{Interpretive content analysis of the class diary}

The class begins with the following question: 
A. Does the distance between the light source (flashlight) and an object have an influence on the length of the shadow of that object?

The groups make predictions.

There are different predictions around the class:

- one that supports the idea that, as the distance between the object and the light source (flashlight) decreases, so will the size of the object's shadow. Examples: "we think that, if the object is closer to the light, its shadow gets smaller, because the light is closer" (Daniela); "I think that if we move the flashlight away, the shadow will be bigger and if we move it closer, the shadow will be smaller” (Bárbara).

- another that supports the idea that, as the distance between the object and the light source (flashlight) decreases, the shadow of the object gets larger. Examples: "I think that, as we move the flashlight closer, the shadow gets bigger, but if we move it farther away, it gets smaller" (Diogo). (...) "Very close to the flashlight, the object gets smaller and farther away like this; it gets bigger” (Bruna).

B. What do we need to do to find out if the distance between the flashlight and the object influences the length of the shadow?

They build an investigation plan.

Encouraged by the teacher's reflective questioning and interacting with their colleagues, the students mentally design a research plan, which will be implemented within each group. The plan includes the following elements:

$\mathrm{B}_{1}$ - The independent variable.

Spontaneously, the students' thoughts begin focusing on the distance between the flashlight and the object. Some of them suggest operational procedures. Examples:

"We could pick up an object and then move the flashlight closer and further away, to see if the shadow is the same or is different" (Joel). "We have to place the flashlight first close to the object, then at an intermediate distance and then far away from the object" (Eva). "We have to place the object at different distances, to find out more things" (Bruna).

$\mathrm{B}_{2}$ - They operationalized the independent variable.

Will it be enough if we use only two distances?

The students suggest using three different distances between the flashlight and the object. Examples:

“(...) the first distance can be $10 \mathrm{~cm}$ (Joel); the second can be $20 \mathrm{~cm}$ ” (Leonardo); "and the last can be $30 \mathrm{~cm}$ " (Eva); "that is too much" (Ângelo); "we'll make $5 \mathrm{~cm}$ differences, then” (Eva); “10 cm, $15 \mathrm{~cm}$ and $20 \mathrm{~cm}$ ” (Lara). The class agrees with the three distances suggested by Lara. "And how are we going to measure those distances?" - Teacher. "With the ruler" (several).

$\mathrm{B}_{3}$ - They identify and operationalize the dependent variable.

"And then, what do we have to measure to know if the shadow depends on the distance between the object and the flashlight?" "The length of the shadow" (Francisca). "And how do we measure the length of the shadows?" "With the ruler" (several children). "And where will we cast the object's shadow?" - Teacher. "On a sheet of cardstock, say Eva and Bruna. Where will we put it?” - Teacher. Bárbara suggests placing the cardstock vertically, propped up between "two tables". "Where will we record the measurements we take?" - Teacher. "On a table, as we did in the other research project” (Leonardo and Lara).

$\mathrm{B}_{4}$ - They identify and operationalize the controllable variables.

- The object to be used for the investigation - "How should the object be, for our investigation?" - Teacher. "I think it has to be always the same" (Daniela); "the object has to be always the same, otherwise, we will not know" (Angelo); "if we use different objects, they will cast different shadows" (Joel); When asked why the objects have to be the same size, some children state: "because the shadow has to do with the size of the object" (Joel); "if an object is larger than another, the shadow can be bigger or smaller" (Daniela); 
- $\quad$ The flashlight and the positioning of the light beam - "How should the flashlight be?" - Teacher. "It must always be the same” (Lara). 2And how should we place it?” - Teacher. "On the table, in front of the targetcardstock" (Leonardo). "How far away from the cardstock should we put the flashlight?" - The teacher asks. Several children say "30 cm", but Joel thinks it is better to place it "40 or $50 \mathrm{~cm}$ away, so we can see the shadow better". The groups agree that the distance between the flashlight and the cardstock will be $40 \mathrm{~cm}$. The different distances between the flashlight and the object - an eraser - will be $10 \mathrm{~cm}, 15 \mathrm{~cm}$ and $20 \mathrm{~cm}$. The students also decide that the flashlight must remain fixed, always in the same place, and it should be the object that moves to the different positions.

C. They execute the investigation plan within each group.

After mentally constructing and clarifying the set of actions to perform, the students execute the plan within each group. The groups are provided with the necessary equipment: identical flashlights; equal erasers - the object to place at different distances of the flashlight; a $40 \mathrm{~cm}$ x $40 \mathrm{~cm}$ cardstock target; a ruler and the individual record sheet. As they encounter difficulties, the groups are encouraged and helped by the teacher. The greatest difficulty felt by the children was the marking of the different distances between the flashlight and the object - the eraser.

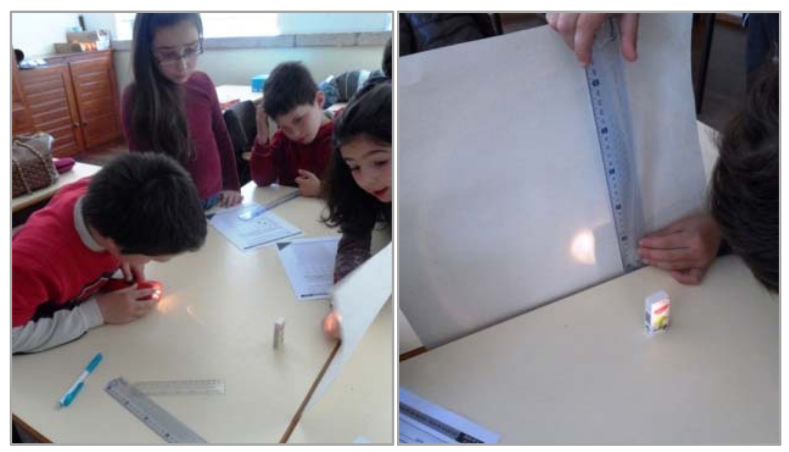

Figure 1. The students execute the investigation.

D. They record the results obtained in each group.

The groups record, and report to the class, the length of the shadow of the object, at each of the three considered distances between the object and the flashlight.

Table 1. Results records.

\begin{tabular}{|c|c|c|c|c|c|}
\hline \multicolumn{2}{|c|}{$\begin{array}{c}\text { Distance between the light source } \\
\text { and the object }(\mathrm{cm})\end{array}$} & \multicolumn{4}{|c|}{$\begin{array}{l}\text { Length of the shadow of the object by } \\
\text { group (cm) }\end{array}$} \\
\hline & & Group 1 & Group 2 & Group 3 & Average \\
\hline Distance A & 10 & 16 & 15 & 16 & 15.7 \\
\hline $\begin{array}{c}\text { Distance B } \\
-1\end{array}$ & 15 & 13 & 12 & 12 & 12.3 \\
\hline $\begin{array}{l}\text { Distance } \\
\square=\square\end{array}$ & 20 & 10 & 10 & 10 & 10 \\
\hline
\end{tabular}


E. They draw conclusions from the data obtained

The students' attention is focused on the average length of the shadows, obtained at each of the distances considered, and they are encouraged to draw their conclusions.

"Why are there differences in the length of the shadows of the objects?" - Teacher. The children express their ideas: "I have concluded that when we move the object away from the light source, the shadow will get smaller" (Eva); "the shadow decreases when the object is moved away from the flashlight" (Lara); "and when we move it closer, the shadow gets bigger" (Bruna); "when we move the object farther away, the shadow gets smaller ... the smaller the shadow" (Daniela); "in the beginning, we were saying it was the opposite” (Joel); "that was what I said” (Guilherme); "we should never take something as certain" (Joel); "the smaller the distance between the object and the flashlight, the greater the length of the shadow and, the greater the distance, the smaller the shadow" (Francisca); "if the distance was $25 \mathrm{~cm}$, the shadow would be smaller” (Daniela); "because, as the distance increases, the shadow decreases” (Francisca); “... it gets smaller” (Joel).

F. They collectively construct the research report

At the end of the class, the students collectively construct the research report. The final narrative, resulting from the various interventions by the children, is as follows:

"We begin by reflecting on the following: does the distance between the object and the light source (flashlight) have an effect on the length of the shadow?

All groups said it does, but their explanations were not the same. Some thought that when the object moved away from the flashlight, the shadow grew larger and when it moved closer to the flashlight, the shadow grew smaller. Contrarily, others thought that when the object moved closer to the flashlight, the shadow grew larger and when it moved away, the shadow grew smaller.

To find out the answer, we conducted an investigation, using the following materials: a flashlight, an eraser, a ruler and a cardstock sheet. We measured the distance between the cardstock and the flashlight $(40 \mathrm{~cm})$ and then we measured three different distances from the flashlight to the eraser $(10 \mathrm{~cm}, 15 \mathrm{~cm}, 20$ $\mathrm{cm})$.

We turned on the flashlight and pointed it at the eraser. We saw the shadow of the eraser on the cardstock and measured its length. We placed the object at a different distance and measured the length of the shadow again. We repeated the experiment, placing the eraser farther away from the light source. We recorded these measurements on a table, calculated the average values and built a graph with the distance from the light source to the object and the length of the shadow.

We have concluded that the further away the object was from the flashlight, the smaller the shadow. And the closer the object was from the flashlight, the larger the shadow".

\section{FINAL CONSIDERATIONS AND CONCLUSION}

The data obtained from the various collection methods used is still in the process of treatment and analysis. The results presented above are only a small part of the results obtained in the study. However, they contain some elements that provide answers to the research questions formulated as the goals for this study. They suggest that, in order to plan and implement a research project, children aged 7/8 years require a high level of scaffolding to reduce the difficulty of the task and allow students to gradually build a coherent strategy to provide an answer to the research problem. In this sense, the teacher's role is crucial. Through questioning, which encourages reflection and action in students, the teacher, as is necessary, helps, encourages and regulates the cognitive activity of students. On the other hand, the initial mental planning and clarifying of the research strategy, in a context of large group collaboration, appears to be a fruitful pedagogical strategy and students can subsequently execute it within each group with some autonomy.

\section{ACKNOWLEDGMENTS}

This work was partially supported by FEDER through the COMPETE Program and by the Portuguese Foundation for Science and Technology (FCT) in the framework of the Strategic Project PEST-C/FIS/UI607/2011. 


\section{REFERENCES}

[1] M. C. Linn, E. A. Davis e P. Bell, Internet environments for science education, London: Lawrence Erlbaum, 2004.

[2] National Research Council, "Inquiry and the national science education standards: A guide for teaching and learning,” National Academy Press, Washington, DC, 2000.

[3] B. Drayton e J. Falk, “Tell-tale signs of the inquiry-oriented classroom,” NASSP Bulletin, vol. 85, n. ${ }^{\circ} 623$, pp. 2434, 2001.

[4] W. Harlen, “Evaluating Inquiry-Based Science Developments.,” 11 May 2004. [Online].

[5] P. Cuevas, O. Lee, J. Hart e R. Deaktor, "Improving Science Inquiry with Elementary Students of Diverse Backgrounds,” Journal of Research in Science Teaching, vol. 42, n. 3, pp. 337-357, 2005.

[6] F. Abd-El-Khalick, S. Baujaoude, R. Duschl, N. G. Lederman, R. Mamlok-Naaman e A. Hofstein, "Inquiry in science education: International perspectives,” Science Education,, vol. 88, n. 3 3, pp. 397-419, 2004.

[7] K. Kask e M. Rannikmäe, “Towards a model describing student learning related to inquiry based experimental work linked to everyday situations,” Journal of Science Education, vol. 10, n. ․ 1, pp. 15-19, 2009.

[8] B. Cavas, "The meaning of and need for "Inquiry Based Science Education (IBSE)," Journal of Baltic Science Education, vol. 11, n. ${ }^{\circ}$ 1, pp. 4-6, 2012.

[9] ME, “Organização Curricular e programas Ensino Básico - $1^{\circ}$ Ciclo,” Ministério da Educação. Departamento de Educação Básica, Mem Martins, 2004.

[10] J. Sá, Renovar as Práticos no $1^{\circ}$ Ciclo Pela Via das Ciências da Natureza, Porto: Porto Editora, 2002.

[11] S. Larkin, “Collaborative Group Work and Individual Development of Metacognition in the Early Years,” Research in Science Education, vol. 36, pp. 7-27, 2006.

[12] W. Harlen, Enseñanza y aprendizaje de las ciencias. (2ª ed. atualizada), Madrid: Ediciones Morata, 2007.

[13] J. G. Sá, “Diary Writing: An Interpretative Research Method of Teaching and Learning,” Educational Research and Evaluation, vol. 8, n. ${ }^{\circ}$ 2, pp. 149-168, 2002.

[14] M. A. Zabalza, Diarios de clase: un instrumento de investigación, Madrid: Narcea, 2004. 